\title{
QUALITY EVALUATION OF INTERNET PURCHASES: THE CASE OF CLOTHING SECTOR
}

\author{
Dalia Mikutavičiūté ${ }^{1}$, Juozas Ruževičius ${ }^{2}$ \\ ${ }^{I}$ Vilnius University, Lithuania, dalia.mikutaviciute@gmail.com \\ ${ }^{2}$ Vilnius University, Lithuania, juozas.ruzevicius@ef.vu.lt \\ cross $^{\text {ref }}$ http://dx.doi.org/10.5755/j01.em.17.1.2291
}

\begin{abstract}
Internet purchases is a phenomenon that rapidly grow in popularity, therefore increasing competition between internet shopping websites brings to one's attention the importance to properly evaluate quality of these services as well as to know what quality factors are most important for customers and have influence on their decision to buy online. Quality evaluation of internet purchases is important for all parties of this business. The aim of this paper is to prepare the model of internet purchases process and in accordance with this model to identify clothing sector internet shopping websites the most important quality factors for Lithuanian customers.

The factors mostly mentioned in literature are related to content quality of website and its technical and ease-of-use aspects. In this paper authors propose internet purchases quality evaluation model, where 5 purchase stages are distinguished and ascribable quality factors are assigned for each stage. Created model helps to have a look into internet purchase process from a different angle than it was done by other authors. Whereas the model offered in this paper could be more effective, on purpose to use it in practice and to evaluate particular internet shopping site's strengths and weaknesses, also in pursuance of its better quality. Accomplished approbation of the offered model and its successive adjustment confirmed the practical application of this model for evaluation of clothing sector objects of internet purchases. Although the model was created purely on the basis of clothing sector's example it can be easy adapted for the evaluation of other sectors' quality factors, because flexibility and adaptability are the main advantages of this model.

Keywords: internet purchases, quality evaluation, model, internet purchase process, internet shopping websites, quality factors, SERVQUAL model.

JEL Classification: L19, L81, L86.
\end{abstract}

\section{Introduction}

Rapid growth of internet purchases determined not only mutual benefit for online customers and sellers, but also the attendant problems of this phenomenon, such as mistrust of internet shopping websites. With the expansion of internet purchases also grows the number of internet crimes, which raises customers' mistrust of internet purchases. According to the Gartner Research Company more than 5 million U.S. customers have suffered losses of adulteration of electronic identification means and fraud cases, which from 2007 to 2008 increased by 40 percent. In 2007 USA customers lost more than 1.2 billion dollars. The USA Federal Trade Commission received 800 thousand customer complaints on e-falsification. VeriSign research findings show, that the USA retail companies didn't get 21 billion dollars because of customers mistrust and fear of personal data leakage. $12 \%$ customers who have suffered loss due to falsification, stopped buying online, $25 \%$ buy less, $19 \%$ spend less money online (Guseva \& Ruževičius, 2009). Similar trends remain recently, therefore more objective internet purchase quality measurement and assessment is very important from the standpoint of increasing trust in internet purchases.

The biggest shortage of existing internet purchases quality evaluation models such as SITEQTUAL (Yoo \& Donthu, 2001), E-S-QUAL (Parasuraman et al., 2005) etc., is that they are too general and intended for universal application, however it is known, that what is universal in fact not always and not everywhere is applicable. Also, most models were created almost a decade ago, so it is important to check whether quality factors identified in these models are still relevant for today's customer. For these reasons there is a need to explore internet purchase process more properly and check importance of quality factors, therefore the aim of this paper is to prepare the model of internet purchases process and in accordance with this model to identify clothing sector internet shopping websites the most important quality factors for Lithuanian customers.

This paper analyses the following scientific problem: a lack of literature for internet purchases quality evaluation prevents not only to unambiguously perceive and generalize structure of this object, but also to professionally evaluate the methods and criteria. That is why from a theoretical and applied point of view it is relevant to define internet purchases content and to prepare quality evaluation methodology for this object, which could be adapted for particular internet purchases fields. 
The research methods: scientific literature review and systematic analysis, scientific studies, which describe internet shopping and/or internet purchases evaluation models and criteria, content analysis, survey and testing for primary data collection, systematic analysis and comparison of results. Research data was processed with statistical analysis program SPSS. Descriptive statistics methods were used for data analysis (means calculations, correlation analysis, etc.). Features of the author's research are presented in paragraph 3.1.

\section{Traditional service quality}

Traditional services in this paper are non-internet-based services, and quality of these services can be defined as conformance to customer requirements (Parasuraman et al., 1985). Mentioned definition is correct, but too abstract, therefore more often it is stated, that service quality is difference between customers' expectations for service performance and their perceptions of the service received (Grönroos, 1984; Asubonteng et al., 1996). In this definition specifications of aforementioned customer are extended and important becomes not customer requirements itself, but difference between what customer expected and what received.

Traditional service quality studies in the literature are divided into two parts (Gummesson, 1989; Santos, 2003):

1) Scandinavian, with the main representative Grönroos. Contribution of this author to service quality assessment is quite important: created model shows that the customer perceived service quality consists of the expected service quality and experienced service quality, which depends on the technical and functional quality (Grönroos, 1984);

2) American with Parasuraman, Zeihaml and Berry contribution for service quality evaluation. Main studies: a) based on focus groups study distinguished 10 service quality dimensions: tangibles, reliability, responsiveness, communication, credibility, security, competence, courtesy, understanding/knowing the customer, access (Parasuraman et al., 1985); b) Service quality establishment function - fulfillment of customer expectations depends on three variables: particular customer expectations, perceived process and final result quality (Parasuraman et al., 1985); c) SERVQUAL model (Parasuraman et al., 1988), which aim was deeper analysis of gap between customer expectations and perceived quality. Based on ten previously established quality dimensions, Likert scale with 97 statements was created, which measures customer expectations for service companies in general and customer experienced quality in particular company (Parasuraman et al., 1988).

Accomplished survey result was the new model, in which only five of 10 quality dimensions remained ( 3 original ones: tangibles, reliability, responsiveness and 2 combined ones - assurance and empathy), and the questionnaire was reduced to 22 statements. The authors maintain that questionnaire is like a skeleton, which is possible to adapt for a wide range of service companies for identifying gap between customers' experienced quality and their expectations. It is possible because there are two analogical sides of one statement used in the questionnaire (Parasuraman et al., 1988).

Despite the fact that SERVQUAL model received some criticism for a variety of topics, such as Likert scale usage, model validity, data variation in other studies, un-universal dimensions, questionnaire complexity, etc. (Asubonteng et al., 1996), it was widely used: it is estimated that by 2002 this model was described or attempted to adapt in more than 100 scientific articles (Wolfinbarger \& Gilly, 2003). Assessment of traditional services' quality with the purpose to find out how the customer understands the quality and distinguish quality dimensions were studied quite detailed.

\section{Internet service quality and its evaluation}

Generally online service is an interactive, content-centered and Internet-based customer service, driven by the customer and integrated with related organizational customer support processes and technologies with the goal of strengthening the customer-service provider relationship" (De Ruyter et al.,2001). From given online services description main differences between these and traditional services come out: interactivity, nature of the customer's participation, relation between customer and service provider.

Customers of online services are not passive receivers of sales, but central persons who have more control in an online environment (Kuo et al., 2005). In internet based services direct contact between customer and company employees disappears, interaction between the customer and website emerges. 
Looking at the online services from internet shopping perspective, following online service definition should fit best: "e-service quality is defined broadly to encompass all phases of a customer's interaction with a website, the extent to which a website facilitates efficient and effective shopping, purchasing and delivery" (Parasuraman et al., 2005). In this paper the concept of online service is defined as e-commerce category business to customer, where the customer is natural person who buys in retail online shops.

In accordance with analysed literature all quality of online services evaluation models can be divided in two parts: models based on SERVQUAL model and new developed online service evaluation models. In order to evaluate the online service quality dimensions more accurately models of both groups were analysed.

Table 1. Comparison of models developed based on SERVQUAL model

\begin{tabular}{|c|c|c|c|}
\hline $\begin{array}{c}\text { E-QUAL } \\
\text { (Kayanama and } \\
\text { Black, 2000) }\end{array}$ & Van Iwaarden et al., 2003 & Long and McMellon, 2004 & Lee and Lin, 2005 \\
\hline $\begin{array}{l}\text { Accessibility; } \\
\text { Navigation; } \\
\text { Design and } \\
\text { presentation } \\
\end{array}$ & $\begin{array}{l}\text { Functionality; Good-looking } \\
\text { Web site }\end{array}$ & Functionality; Attractiveness & Web site design \\
\hline $\begin{array}{l}\text { Content and } \\
\text { purpose }\end{array}$ & $\begin{array}{l}\text { Tax and/or other charges } \\
\text { clarity; Accessible sale } \\
\text { terms and conditions; } \\
\text { Registration and access } \\
\text { process is simple } \\
\end{array}$ & $\begin{array}{l}\text { Company does, what promised; } \\
\text { Services without need to contact } \\
\text { company; Easy access and } \\
\text { understanding of billing }\end{array}$ & $\begin{array}{l}\text { Correct orders fulfilling; } \\
\text { Secure personal } \\
\text { information; Prompt } \\
\text { delivery }\end{array}$ \\
\hline Responsiveness & $\begin{array}{l}\text { Access speed; Fast solving } \\
\text { of queries or complaints }\end{array}$ & $\begin{array}{l}\text { Prompt service; Fast solving of } \\
\text { requests and willingness to help }\end{array}$ & $\begin{array}{c}\text { Promptly respond to } \\
\text { customers inquires; } \\
\text { Information retrieval and } \\
\text { navigation speed }\end{array}$ \\
\hline $\begin{array}{l}\text { Personalization; } \\
\text { Customization }\end{array}$ & $\begin{array}{l}\text { Personalization; Accuracy } \\
\quad \text { of provided links }\end{array}$ & $\begin{array}{c}\text { Individual attention for } \\
\text { customers; Satisfy customer } \\
\text { needs }\end{array}$ & $\begin{array}{c}\text { Personalization: } \\
\text { individualized attention, } \\
\text { personal thank you notes }\end{array}$ \\
\hline \multirow[t]{3}{*}{ Background } & $\begin{array}{l}\text { Information about products } \\
\text { and company; Security and } \\
\text { privacy policies are } \\
\text { accessible; Trustworthiness }\end{array}$ & $\begin{array}{l}\text { Customers should feel safe; } \\
\text { Secure transactions; Privacy } \\
\text { assurance; Internet site should } \\
\text { operate all the time }\end{array}$ & Online trust \\
\hline & & $\begin{array}{l}\text { COMMUNICATION: Clear } \\
\text { instructions; Follow-up for order } \\
\text { confirmation }\end{array}$ & \\
\hline & & $\begin{array}{l}\text { ORDERING/SHIPPING/ } \\
\text { PACKAGING: Variety of } \\
\text { shipping options; Acceptable } \\
\text { return policy; Merchandise } \\
\text { shipping in good packaging }\end{array}$ & \\
\hline
\end{tabular}

Source: designed by the authors

As it is shown in the table above authors tried to link online services quality evaluation with SERVQUAL model, which was created for quality evaluation of services in general. In one of mentioned papers (table 1) it was attempted to create a model for online travel agencies quality evaluation (Kayanama $\&$ Black, 2000), in another paper chosen research area was websites and purpose to prove that SERVQUAL model is easy to adapt for quality evaluation of websites (Van Iwaarden et al.,2003). Selected areas in third (Long \&McMellon, 2004) and fourth (Lee \& Lin, 2005) papers were internet shopping and authors' researches are different compared to others not only because of the attempt to use dimensions of SERVQUAL model, but also to create new dimensions, more suited for internet shopping quality evaluation.

Long and McMellon added two more dimensions to the existing SERVQUAL model in their research: communication and ordering, shipping and packaging dimension, which were merged into one dimension "buying process" after analysis and calculations (Long \&McMellon, 2004). Compared to the firstly analyzed models and SERVQUAL last research was changed the most - original dimensions' names were changed to more suitable for internet shopping, authors didn't count difference between customer expectations and 
perceived service quality, but tried to calculate general view about service quality and satisfaction level (Lee \& Lin, 2005). Summarizing mentioned studies based on SERVQUAL model it could be noticed, that importance of SERVQUAL model was proved once again, as well as what impact it made for traditional service quality (although it was widely criticized), also remained popular after online services emergence.

As mentioned before, second part of online service quality evaluation models was new developed online service evaluation models, which were chosen for further analysis on the basis that their quality dimensions and interpretation of these quality dimensions differ, also that they could be identified by name and would have been mentioned in two or more studies from other authors. In order to highlight their nature, characteristics and differences contents of these models will be briefly described.

1. SITEQUAL. The authors identified four quality dimensions according to conducted interviews: ease-of-use, aesthetic design, processing speed and security (Yoo \& Donthu, 2001);

2. WEBQUAL ${ }^{\text {TM }}$. After student surveys (three stages) and collected information analysis authors formed final quality evaluation model of online services, which consists of 12 dimensions divided into four categories: ease-of-use (easy understanding and intuitive operations), entertainment (visual appeal, innovativeness and emotional appeal), usefulness (informational fit-to-task, tailored communications, trust and response time), complimentary relationship (consistent image, online completeness, relative advantage) (Loiacono et al., 2003);

3. .comQ/EtailQ. Development of the model was based on focus groups research. According to the focus groups research results survey was designed and an online survey was conducted. After statistical calculations were performed, . $\operatorname{com} Q$ model was developed. This model consists of four dimensions: customer service, security/privacy, website design, fulfillment/reliability (Wolfinbarger \& Gilly 2003);

4. $\boldsymbol{E}-\boldsymbol{S}$ - $\boldsymbol{Q} \boldsymbol{U} \boldsymbol{A} \boldsymbol{L}$ model is designed exclusively for quality evaluation of internet shopping websites and unlike other models include entire internet purchases process. The model consists of two parts: the main $(E-S-Q U A L)$, designed for all internet shopping sites customers, and the e-recovery service quality scale (E-RecS-QUAL), which is required only for those customers, who have had problems with internet shopping websites (Parasuraman et al., 2005).

Quality dimensions of the main part E-S-QUAL are: efficiency, fulfilment, system availability, privacy; while E-RecS-UAL dimensions are: responsiveness, compensations, contact (Parasuraman et al., 2005).

$E-S-Q U A L$ model has been tried to modify and renamed into $E-A-S-Q U A L$ by analysing internet shopping websites for women clothes (Kim et al., 2006). The authors of this model stated that compensation dimension is inappropriate, because it cannot be measured without actual problems, so three more dimensions were added to $E-A-S$ - $Q U A L$ model (except compensation): personalization, information (general company and product related information), and graphic styles (Kim et al.,2006).

There were 4 models analysed, also one of their modifications and four studies, in which it was attempted to adapt SERVQUAL model for quality of online services evaluation. In studies, where SERVQUAL model was adapted (Kayanama \& Black, 2000; Van Iwaarden et al.,2003; Long \& McMellon, 2004; Lee \& Lin, 2005), identified quality dimensions were specified much more by assigning different quality factors for them. The reason could be that authors were trying to adapt already created SERVQUAL model for online services. In order not to depart from SERVQUAL model more detailed descriptions and generalizations were needed. On the contrary, authors who created their own models, designed for evaluation of online services quality, proposed new dimensions in more general way.

Despite the fact that studies for defining quality factors and dimensions were different, there are some equal dimensions between models. Most common dimensions are responsiveness, reliability, security and functionality; these recurring dimensions allow doing presumption, that these dimensions are the most important in internet shopping websites quality evaluation. Meanwhile there are also unique dimensions, for example compensation and system availability -E-S-QUAL (Parasuraman et al., 2005), customer service (Wolfinbarger \& Gilly, 2003).

Student surveys were one of most common information sources for studies. Impact for this might have been sudden spread of internet shopping websites and belief that students are most active members of society, innovation fans and frequent internet buyers (Yoo \& Donthu, 2001). 


\section{Formation of new model}

Authors of analyzed models sought to create models that can be applied in practice and results of researches can be used for internet shopping websites development. However, it should be remembered that in these innovation times not only technology, but also customers preferences and expectations change very rapidly, therefore most internet shopping quality evaluation models can be hard to implement or they don't reflect today's realities. For this reason it was decided to group internet purchase process into smaller components - internet purchase stages with ascribable quality factors for each stage.

Quality factors and dimensions, identified in the analysed models, as well as models themselves have advantages and disadvantages, so in order to generalize and apply them for internet purchase process new model should be designed.

In designed theoretical model 5 purchase stages with ascribable quality factors for each stage are base of theoretical model. The service is marked as a separate component of the model. Service is important in all purchase stages; therefore it is added not as a continued criterion, but as a stage having influence for all stages with all of its quality factors. Summing up analysed literature, all quality dimensions with ascribable quality factors were divided into groups according to belonging to a purchase stage and joining them by implication. Below there are all stages and ascribable quality factors (including services):

1. Login and search for product. This internet purchase part consist of 4 quality factors, which are especially important because they are primarily noticeable on customers and have impact for their further behaviour - page navigation or logoff the website. Mentioned quality factors are accessibility, visual appeal or website design, functionality and accuracy of information;

2. Product order. In this stage three quality factors could be important: registration and privacy, variety of shipping options, submission of order confirmation details;

3. Payment for the product. Distinguishable quality factors are following: security, different payment options and their clearness, clearly detailed tax and/or other charges, payment receipt confirmation;

4. Product receipt (not product delivery, because this internet purchase process is viewed from the customer's perspective), which consist of speed of delivery and contract fulfilment;

5. Product return. It consist of two quality factors: return policy and return loss compensation;

6. Service. Five quality factors: personalization, reliability, responsiveness, communication, system availability.

Created theoretical model should help to evaluate internet purchase quality factors more objectively and efficiently than models analysed before. The authors of these models did not create process or analysed different internet purchases stages, but just excluded quality factors, looking into it like one unit, therefore models were too generalized.

\subsection{Research methodology}

So far created internet service quality evaluation models are very useful, but it needs to be kept in mind that the language, culture, religion and abundance of other factors can affect customer quality perception (Van Iwaarden et al., 2003). Considering these facts there is a need to investigate what quality factors are important to customers in Lithuania, who shop online in foreign or Lithuanian websites.

The aim of this research: to evaluate quality factors that are important to customers in Lithuania, who purchases clothing sector products online, using the theoretical internet purchase process model. Research is based on internet purchase stages and ascribable quality factors for each stage, which are defined in different statements in created questionnaire. These statements should be evaluated on nine-point scale and such width of the scale is selected because respondents have greater choice and greater distribution of answer could be obtained. The questionnaire contains not only six scales (the scale for each internet purchase process stage), but also: the question-filter to distinguish respondents who purchased clothing sector products online in the last six months - exactly such respondents are the target group; introductory questions enabling to identify the respondents' behaviour, i.e. frequency of internet purchases and in what internet shopping websites they purchase; demographic questions.

According to the Department of Statistics in Lithuania in $20103.2 \%$ of the population aged 16-74, i.e. 83 000, purchased clothing, footwear and sport products on internet (Statistics Lithuania, 2010). Unfortunately it is the only most accurate information of this type found, and it does not fully reflect the size 
of the population $(3.2 \%$ of the population includes not only customers who purchased clothing sector products but also sporting goods and footwear).

Sample (96 respondents) for this research was calculated based on available data and aid of online calculator (Creative Research Systems). So, in order to obtain representative data there is a need to interview 96 respondents, who purchased clothing sector products online during the last 6 months.

\subsection{Research results of quality evaluation of internet purchases in clothing sector}

The Survey "quality evaluation of internet purchases in clothing sector" was implemented in September 2011. Survey publication was stopped when required number of questionnaires was collected, i.e. when in total 96 respondents answered, who purchased clothing sector products online in the last 6 months.

The survey was designed in online surveys' site www.publika.lt and was distributed in online forums and in social networks with the purpose to reach the target group, where topics about purchasing on internet are discussed.

During the survey period 163 respondents participated, 67 of them didn't purchase clothing sector products on internet in the last six months. Demographics of target group respondents: almost three-quarters (70.4 \%) of the respondents were women, more than a half (66.7 \%) respondents belong to age group 25-34 years and nearly one-fourth (24.7\%) of the age group 16-24 years. Most respondents (86 \%) have university education and distribution depending on incomes is relatively high, but the largest part of respondents (24.7 $\%$ ) is the one consisting of respondents whose income is from 1501 to $2200 \mathrm{Lt}$.

In order to verify which demographic rate has impact for online purchases chi-square was calculated. Statistically significant difference $(\mathrm{p}=0.007)$ was found only to income, which means that the answers to the question "Did you purchase clothing sector products in the last 6 months?" selection is significant different depending on the income - a higher income respondents more often chose answer "Yes" to the mentioned question. Distribution of respondents based on the frequency of purchasing clothing products online is shown in figure 1. Purchasing frequency dependence on gender, age, education or income was not confirmed, correlation between all these indicators was also not found.

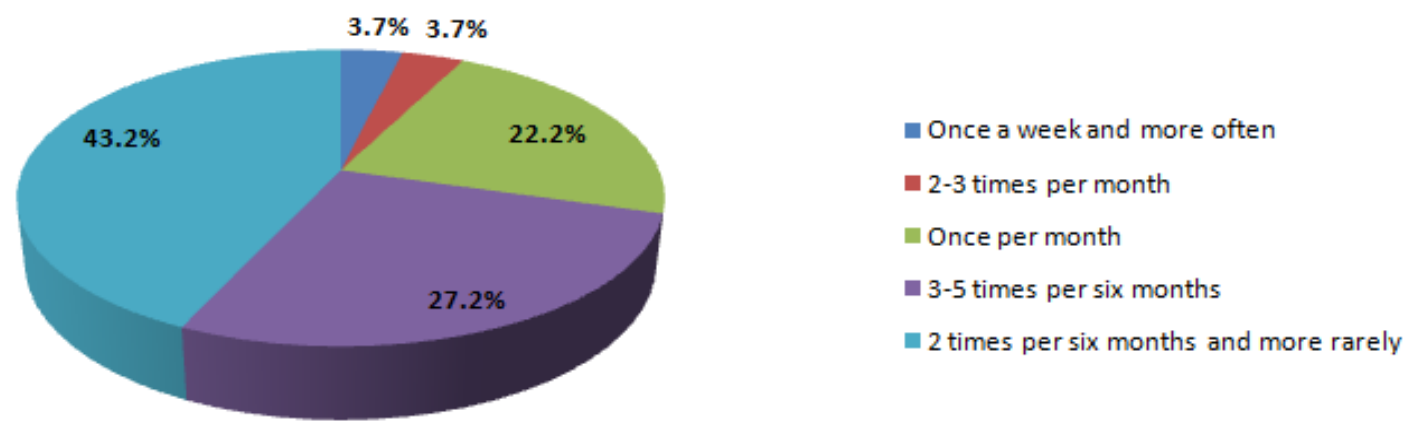

Figure 1. Distribution of respondents by online purchase frequency Source: authors' research results

As it is seen from the picture above, most respondents, even $43 \%$, purchase clothing products online only 2 times per six months, or even more rarely. It can be concluded that purchasing of clothing products online cannot or simply doesn't replace traditional brick-and-mortar firms and it is not very common phenomenon. Only $3.7 \%$ of the respondents purchase clothing products once a week and more often, the same number of the respondents purchase 2-3 times per month.

After introductory questions in the questionnaire the next topic was different online purchase stages and quality factors of these stages' evaluation, dependence on demographic factors, correlation and Cronbach's alpha calculations. Cronbach's alpha in the designed questionnaire is equal to 0.87 .

As the research result analysis showed, there is no general rule for quality factors' evaluation in different stages of purchase process. In some cases importance of evaluation statistically significantly differed depending on gender, in other cases depending on incomes, just as in calculations of correlation between data. Among all identified quality factors there are three ones which women rated as more important than men. These quality factors are accessibility, website design, registration and privacy, so in internet shopping websites, where buyers are women, attention must be paid to the mentioned quality factors. 
Checking whether there is a statistically significant difference between respondents' evaluations, which have ever had returned products purchased online, the results showed that such respondents evaluate following quality factors as more important ones: payment receipt confirmation, personalization and communication.

Results of calculation's correlation showed that:

- Weak and positive correlation exists between purchase frequency and return loss compensation the more rarely clothing products are purchased online, the more important return loss compensation is;

- Weak and negative correlation was found between incomes and variety of shipping options, clearly detailed tax and/or other charges, contract fulfillment and return policy. Importance of all mentioned factors decrease when respondents' incomes increase.

The correlation is weak in all cases, therefore to follow the data obtained isn't possible, and it is more informative.

To evaluate importance of quality factors these factors were detailed and described with the help of different statements. Evaluation of these statements was combined in further analysis (evaluations of particular statements were calculated as average for each respondent) and overall importance evaluation was calculated on quality factors level. Evaluations of quality factors are summarized in Figure 2.

As shown in Figure 2, evaluation of importance of quality factors is similar in some stages of purchase on internet process (for example in product return stage), in others very different (for example service stage). The decision to use not seven-point but nine-point scale was vindicated - factors' evaluation in nine-point scale indicate larger distribution of values, which allows better insight of quality factors importance evaluation. In each internet purchase process stage quality factors were compared among themselves: is there any statistically significant variation in quality factors according to their importance averages. Purpose was to identify such quality factors which stand out of all other quality factors in particular stage by their importance.

In the first stage statistically most important quality factor is accuracy of information, as it is shown in figure 2 its average of importance evaluation is 8.4 and it clearly stands out from other factors in the same stage. Equally there are other factors distinguished by importance: registration and privacy (average 8.12) in product order stage, security (average 8.54) in payment for the product stage and contract fulfillment (average 7.98) in product receipt stage. In product return stage both quality factors are statistically equally important and in service stage most distinguished quality factor is personalization - this quality factor was least important for respondents compared to other quality factors in service stage.

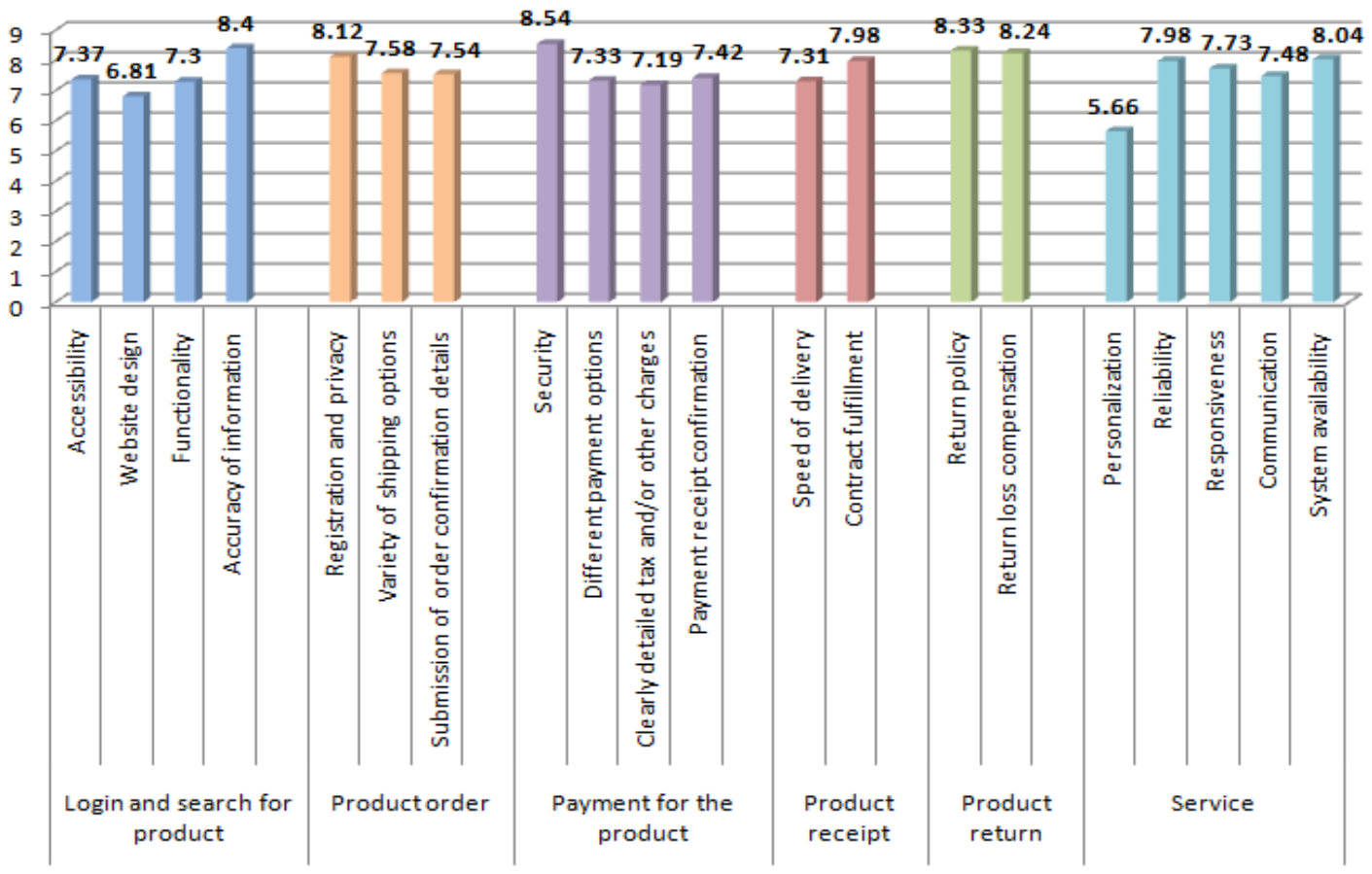

Figure 2.Importance of quality factors in different internet purchase stages comparison Source: authors' research results 
Considering quality factors, which were distinguished by importance in different internet purchase stages, they should be marked accordingly in internet purchase model. Although personalization was evaluated as least important quality factor, it cannot be excluded from the model because average of importance is 5.66, which is larger than the neutral point in the scale. Also, according to the respondents' opinion and seeking for better model clarity, it is possible to exclude internet purchase stages in which particular service quality factors are important, therefore considering all mentioned conditions in Figure 3 adjusted theoretical model of internet purchase is proposed.

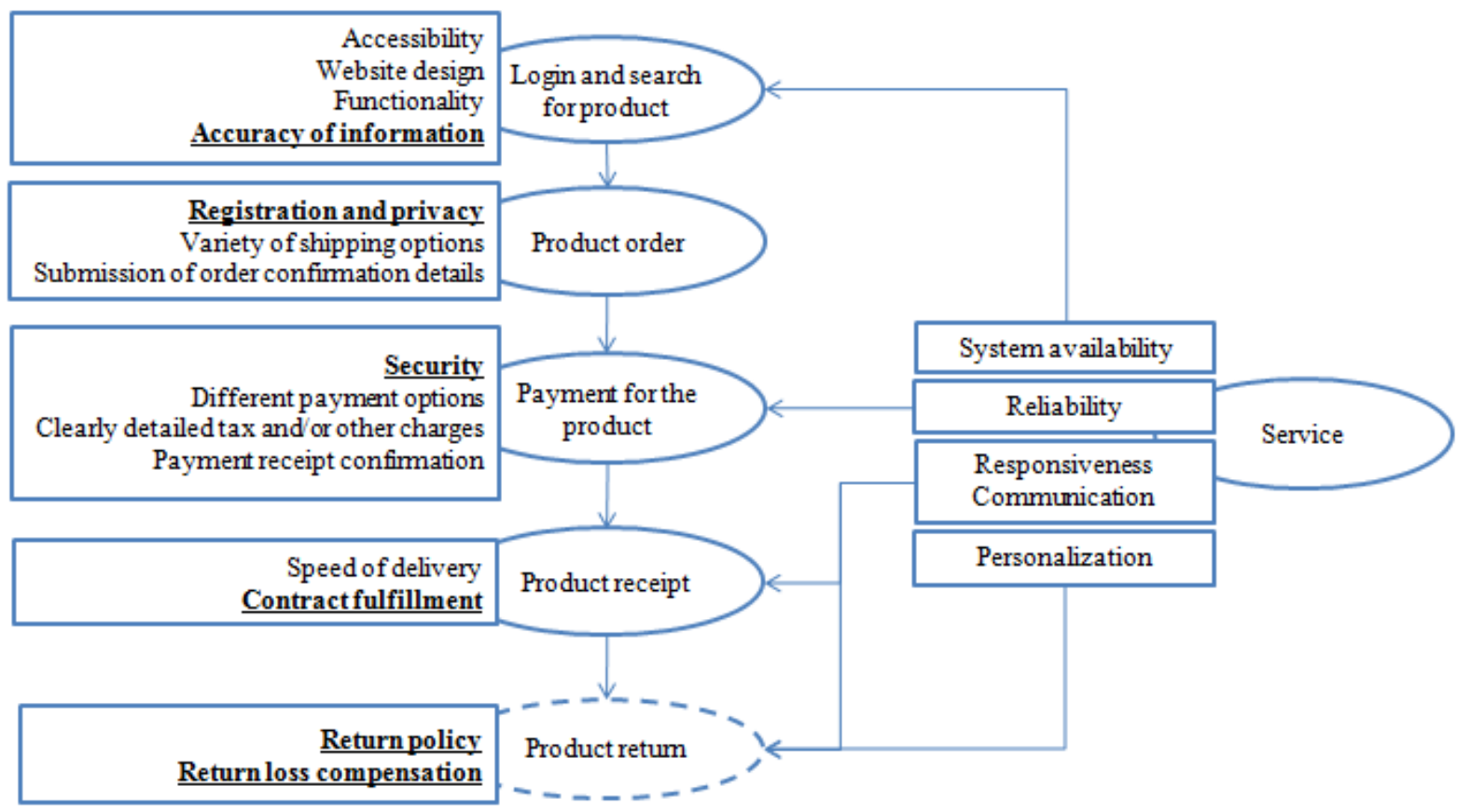

Figure 3. Internet purchase process and quality factors model

Source: model designed, corrected and consolidated on the grounds of authors' research results

As shown in model (Figure 3), there are clearly distinguished main stages of internet purchase process, and quality factors, also arrows graphically show, which quality factor of service stage belongs to which internet purchase stage.

In questionnaire, based on which quality factors' evaluation was made, information found in literature was concentrated, summarized and distinguished in clear statements. The aim was that all quality dimensions and factors mentioned in literature would be reflected one way or another in created statements (some of them were generalized, others presented as they were in literature). The aim of this research was to prepare the model of internet purchases process and in accordance with this model to evaluate importance of quality factors - the aim is achieved.

\section{Conclusions and insight}

The research accomplished on the base of created model allowed identifying the most important quality factors not only for the service quality of internet purchases in general, but also for particular stages of this service, looking at it exceptionally from the customer's perspectives. The new model could help the owners, creators or managers of internet shopping websites, who want to identify the advantages and disadvantages of their websites. This model is also easy to adapt, because it is clearly separated into purchase stages with ascribable quality factors for each stage and it gives the possibility to identify the strengths and weaknesses of quality factors not only in general, but also at different stages' level.

Created model is easy to adapt, only the structure of model could be changed depending on the chosen sector: 1) some internet purchase stages could disappear; 2) Statements used in internet purchase quality evaluation in clothing sector could become quality factors and vice versa.

Flexibility and adaptability of created model are main advantages; however it is only a small part of great opportunities. Further researches should allow creating the methodology for model evaluation, which would enable calculation of the weakest parts of internet shopping website. Measurable and calculable 
criteria should be distinguished and/or created, which would allow objective evaluation of each quality factor and also of each internet shopping website; it could enable comparison of these shopping websites. With the help of different objective criteria it should also be possible to compare and evaluate Lithuanian and foreign internet shopping websites and to find out, why customers often choose foreign internet shopping websites over the Lithuanian ones and what Lithuanian internet shopping websites are missing.

\section{References}

1. Asubonteng, P., McCleary, K. J., \& Swan, J. E. (1996). SERVQUAL revisited: A critical review of service quality. The Journal of Services Marketing, 10, 62-81.

2. Creative Research Systems (2010). Retrieved April 30, 2011, from http://www.surveysystem.com/sscalc.htm.

3. De Ruyter, K., Wetzels, M., \& and Kleijnen, M. (2001). Customer adoption of e-service: an experimental study. International Journal of Service Industry Management, 12, 184-207.

4. Grönroos, C. (1984). A service quality model and its marketing implications. European Journal of Marketing, 18, 36-44.

5. Guseva, N., \& Ruževičius, J. (2009). The certification label as an indication of e-commerce quality and credibility. Current Issues of Business and Law, 4, 53-71.

6. Gummesson, E. (1989). Nine Lessons on Service Quality. The TQM Magazine, 1, February, 166-174.

7. Kaynama, S. A., \& Black, C. I. (2000). A proposal to assess the service quality of online travel agencies: An exploratory study. Journal of Professional Services Marketing, 21, 63-89.

8. Kim, M., Kim, J.-H., \& Lennon, S. (2006). Online service attributes available on apparel retail web sites: an E-SQUAL approach. Managing Service Quality, 16, 51-77.

9. Kuo, T., Lu, I. Y., Huang, C.H., \& Wu, G.C. (2005). Measuring users' perceived service quality: An empirical study. Total Quality Management, 16, 309-320.

10. Lee, G.G., \& Lin, H. F. (2005). Customer perceptions of E-service quality in online shopping. International Journal of Retail \& Distribution Management, 33, 161-176.

11. Loiacono, E., Watson R. T., \& Dale G. (2003). WebQual ${ }^{\mathrm{TM}}$ : A Web Site Quality Instrument. Working paper, Worcester Polytechnic Institute.

12. Long, M., \& McMellon, C. (2004). Exploring the determinants of retail service quality on the Internet. Journal of Services Marketing, 18, 78-90.

13. Parasuraman, A., Berry, L. L., \& Zeithaml, V. (1985). Quality counts in services, too. Business Horizons, 28, 4452.

14. Parasuraman, A., Zeithaml, V., \& Berry, L. (1988). SERVQUAL: A multiple-item scale for measuring consumer perceptions of service quality. Journal of Retailing, 64, 12-40.

15. Parasuraman, A., Zeithmal, V. A., \& Malhotra, A. (2005). E-S-Qual, A multiple-item scale for assessing electronic service quality. Journal of Service Research, 7, 213-233.

16. Santos, J. (2003). E-service quality: a model of virtual service quality dimensions. Management Service Quality, $13,233-246$.

17. Statistics Lithuania (2010). Information technologies in Lithuania. Vilnius. Retrieved 30 April, 2011, from http://www.stat.gov.lt/lt/catalog/list_free_releases?year=2010\&cat_id=all\&x=13\&y=11

18. Van Iwaarden, J., van der Wiele, T., Ball, L., \& Millen, R. (2003). Applying SERVQUAL to web sites: An exploratory study. International Journal of Quality \& Reliability Management, 20, 919-935.

19. Wolfinbarger, M., \& Gilly, M. C. (2003). EtailQ: dimensionalizing, measuring and predicting Etail quality. Journal of Retailing, 79, 183-198.

20. Yoo, B., \& Donthu, N. (2001). Developing a scale to measure the perceived quality of an Internet shopping site (SITEQUAL). Quarterly Journal of Electronic Commerce, 2, 31-45. 